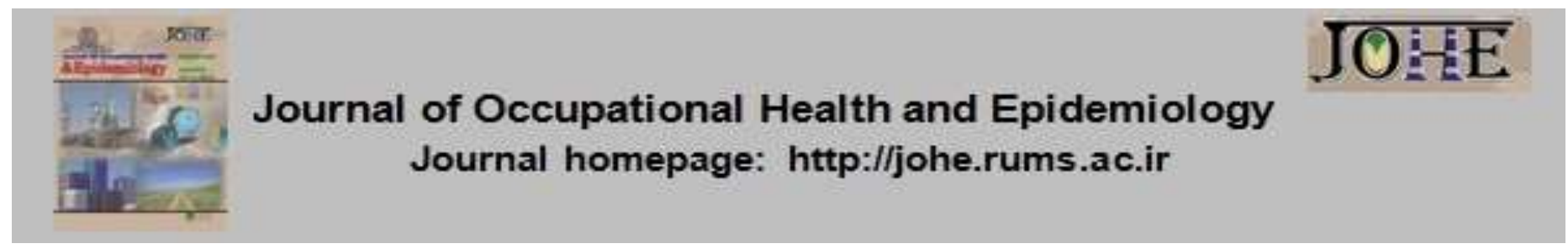

\title{
Diagnosis of the noise emission in a plastic recycling plant located in the municipality of Caçador, Santa Catarina, Brazil
}

\author{
Roger Francisco Ferreira de Campos * \\ - MSc of Environmental Sciences, Alto Vale do Rio do Peixe University, Caçador, State Santa Catarina, Brazil.
}

Citation: Ferreira de Campos RF. Diagnosis of the noise emission in a plastic recycling
plant located in the municipality of Caçador, Santa Catarina, Brazil. JOHE. 2018; 7(3):185-
91.

\section{Article Info}

* Corresponding authors: Roger Francisco Ferreira de Campos,

E-mail: roger@uniarp.edu.br

\section{Article history}

Received: July, 2017

Accepted: March, 2018

10.29252/johe.7.3.185

Print ISSN: 2251-8096 Online ISSN: 2252-0902

Peer review under responsibility of Journal of Occupational Health and Epidemiology

\begin{abstract}
Background: With industrial development, many production processes emit high levels of noise, presenting problems for society. This emission causes an environmental impact on employees and also on the surrounding environment.

Materials and Methods: The present study was performed with the objective of analyzing the noise emission in a plastic recycling plant in the municipality of Caçador, Santa Catarina (SC), Brazil, with the perspective of the environmental suitability with the regulatory environmental agencies.

Results: According to the relevant legislation, the plant had significant noise emission levels, reaching 98 A-weighted decibels [dB (A)], since NBR 10151/2000has permitted the emission of $70 \mathrm{~dB}(\mathrm{~A})$ for industrial areas.

Conclusions: Thus, the plant under study needs to seek for ways to reduce its noise emission in its production process; this issue can be attributed to the isolation of the washing process, as the centrifuges in this process are responsible for generation of main part of the noise. Regarding the occupational hygiene process, the plant needs the distribution of ear protectors due to the emission of noise, seeking the best quality of work for its employees.

Keywords: Noise Pollution, Compliance, Environmental.
\end{abstract}

\section{Introduction}

With the technological development, the industrial processes in turn spread with great negative impact on the environment due to different types of contamination and environmental pollution (1). Noise is one of the main pollutions caused by industrial and productive processes. Since the ear converts energy of sound waves into nerve impulses, which again are interpreted as a sound in the brain. Hence, the sound pressure originated from the noise at high exposure can cause damages to the brain (2).

The sound is a pressure change in the air or in the water which can reach the human ear (3). The noise is the set of undesirable and unpleasant sound and a disturbance to children. The classification of disturbing agents is related to the psychological factor of tolerance of each individual (4). CONAMA Resolution 001/90, item I, presents the noise emission, because of any industrial, commercial, social or recreational activities, including political propaganda, in the interests of health, public and guidelines established in this resolution (5).

The noise systems in contact with the human being becomes a threat to the quality of life (QOL) due to their characteristics of interaction with human body, capability of provoking hearing and affecting individuals psychologically and socially (6). Noise in urban centers can cause sleep loss $(7,8)$ in addition to irritability and insomnia (9). Excessive noise in urban areas can lead to deafness, psychiatric imbalances, and degenerative diseases (10). 
Many production processes are along with significant amounts of noise emission, the examples of which include carpenters, mechanical devices, furniture industry, industrial waste management companies, mechanical metal works, clothing manufacturing factories, crushing process, and plastic recyclers with an emission rate of 101.34 (11), 98.00 (12), 95.1 (13), 105.9 (14), 107.80(15), $97.80(16), 74.50(17)$, and 87.40 (18), respectively. Noise-induced pollution is an unaggressive process, being an invisible pollutant that can cause hearing damage as in the whole organisms (19). Noise is one of the problems of urban development due to its negative effect on the QOL, requiring the interaction or intervention of public policies to reduce this impact in order to reduce urban environmental impact (20). It is necessary to develop and increase the knowledge on noise production areas to take control measures and alternatives to improve the negative effects of noise on health and well-being of the human beings (21).
It is necessary to analyze noise emissions and investigate its effects on the exposed population, since noise reduction requires environmental legislation to protect the population of the area at risk (22). Therefore, the present study was conducted aiming to analyze the interaction of noise emission in a plastic recycling plant with its area of interaction and its production process.

\section{Materials and Methods}

The plant under study was located in the municipality of Caçador, state of Santa Catarina, Brazil, locating $26^{\circ} 46^{\prime} 30^{\prime \prime S}$ and $51^{\circ} 0^{\prime} 54^{\prime \prime} \mathrm{W}$, at an altitude of $920 \mathrm{~m}$ (Figures 1 and 2). The plant under study operates under the class IIB waste recovery process recycling plastic chips (low density and high density polyethylene). Therefore in this study, it was attempted to analyze the plant's interaction with the surroundings in terms of the noise emission.

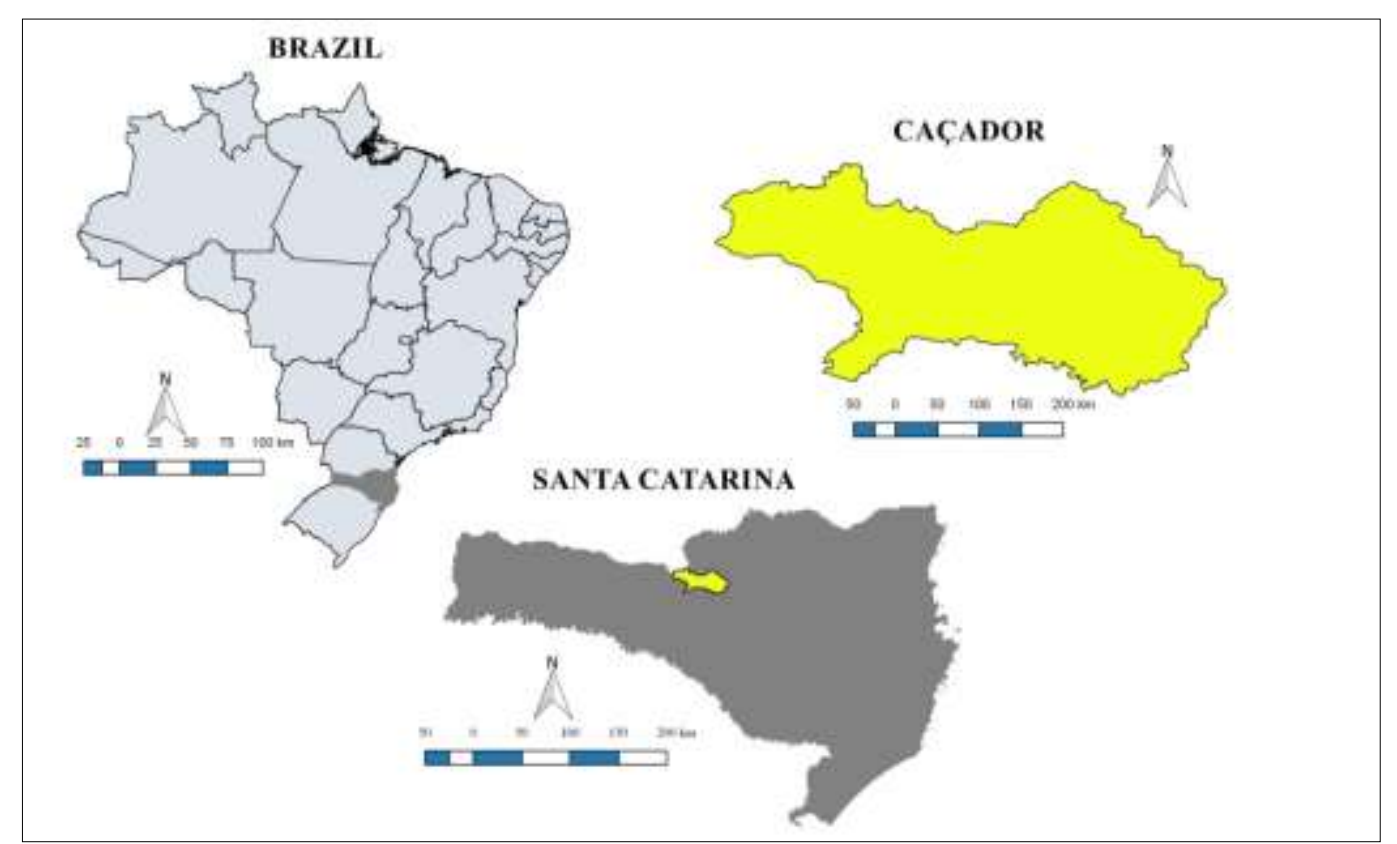

Figure 1: Location of the study area, municipality of Caçador, Santa Catarina, Brazil

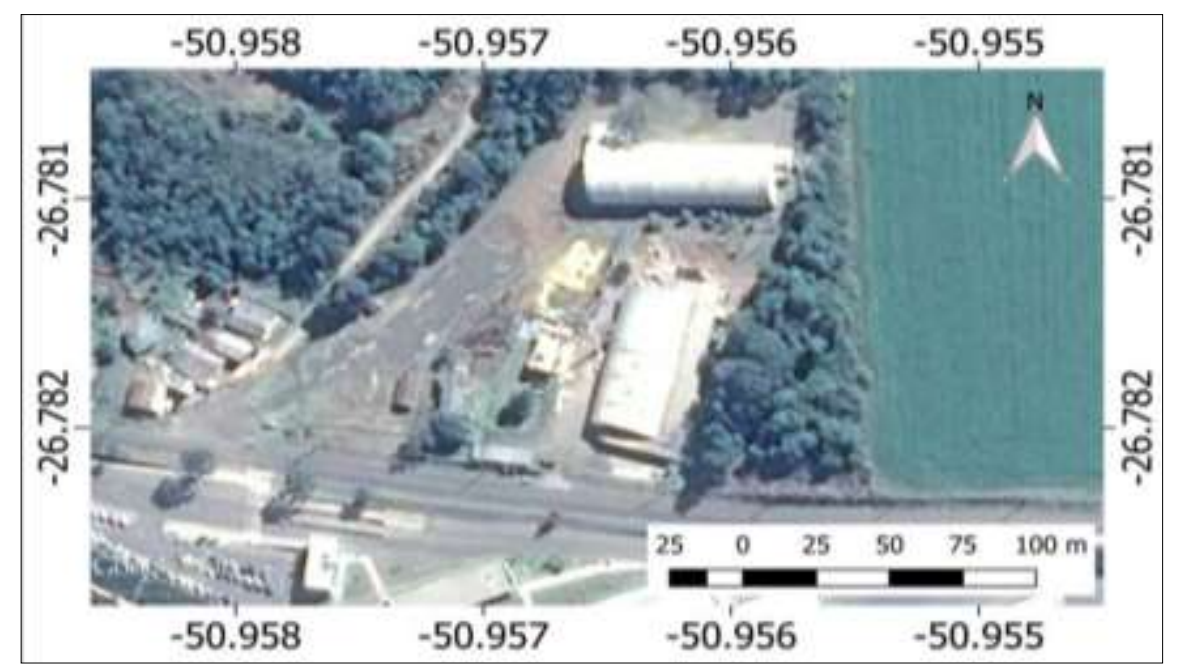

Figure 2: Location of the study area 
The plant operated from 08:00 a.m. to 6:00 p.m. with a break time from 12:00 to 2:00 p.m., operating 12 employees in its production process, being 7 men and 5 women, respectively. The plant's production process consisted of the recovery of plastic (raffia) supplied by recycling companies and cooperatives with different stages (Figure 3). The first stage was the screening process, where the unrecyclable materials (cardboard, glass, metal, etc.) was removed from the raw material. Then, the recyclable material was conveyed to the second stage, termed grinding (Figure $3-\mathrm{A}$ ), where the material was ground in a knife mill.

The third stage included the washing process (Figure 3-A), in which the impurities of the contaminated plastic were removed by the movement of channels in the tank. In the fourth stage, the material was spin in two multi-cyclonecentrifugal turbines for removing the excess water (Figure 3-B) in order to prevent hydrolysis in the granule production process, in addition, to store the material in the plant shed in the later stages (Figure $3-C)$. The fifth and final stage consisted of the plastic agglutination process where the material was extruded, composing the final product of the plastic recycling process (Figure 3-D).

The study was carried out in July 2017. The analysis of the plant's noise emission was performed in terms of the noise emission from all the production processes through different stages including the total production, the plastic washing process only, the extrusion process only, and interrupted production process. This was performed in different sectors of the plant using a duly calibrated decibel with a total of 14 sample points in order to analyze the interaction of the noise with the surrounding area through measuring noise in every 5 minutes in the interval of 1 hour. In order to evaluate the sound pressure level (LAeq), the level obtained from the mean square root (RMS) of the sound pressure (by A-weighted decibels) was used for each measurement interval using equation 1 .

$$
L A e q=10 \log \frac{1}{n} \sum_{i=1}^{n} 10_{10}^{L i}
$$

Where, Li and $n$ are the sound pressure level in $\mathrm{dB}$ (A) read in fast response every 5sduring the measurement of noise and the total number of readings, respectively.

The present study was based on compliance with CONAMA Resolution 01/1990.According to this resolution, the level of sound produced during a process cannot exceed the levels established by NBR 10.152-Noise Assessment in Residential Areas, aiming at the comfort of the community (23). The analysis of variance (ANOVA) was performed on the data and the means were compared by the Tukey's test at $5 \%$ probability level using the ASSISTAT program version 7.7 beta (24).
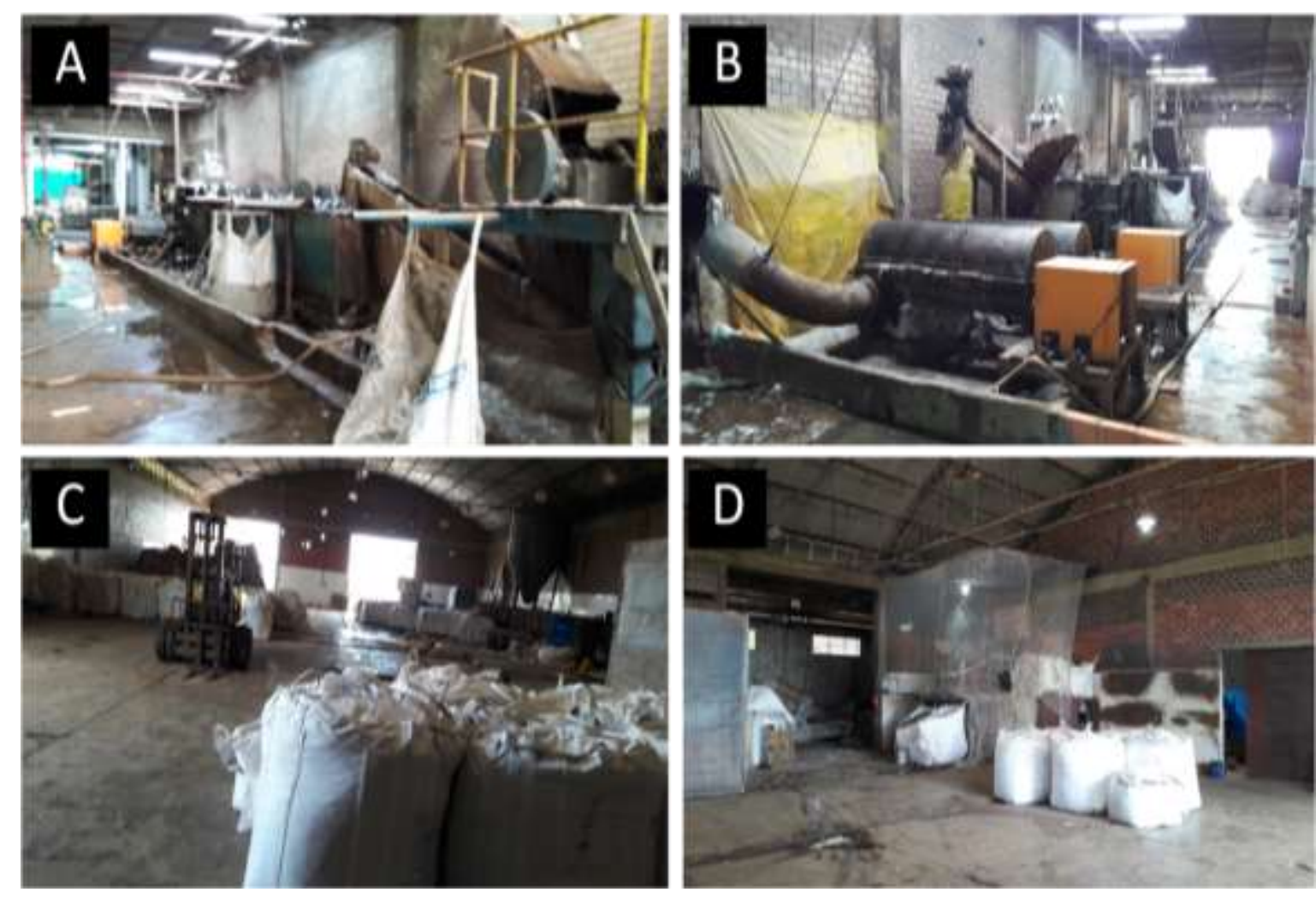

Figure 3: Plastic recycling process of the plant under study: (A) Plastic washing process, consisting of grinding mill and washing tank; (B) Process of centrifuging the washed plastic; (C) Plastic storage tank; (D) and Plastic extrusion process. 
Table 1: Description and location of sampling points

\begin{tabular}{ccll}
\hline Score & Latitude & Longitude & \multicolumn{1}{c}{ Description $^{\star}$} \\
\hline 1 & $26^{\circ} 46^{\prime} 56.90^{\prime \prime}$ & $50^{\circ} 57^{\prime} 23.09^{\prime \prime}$ & Storage area of washed raffia material \\
\hline 2 & $26^{\circ} 46^{\prime} 56.24^{\prime \prime}$ & $50^{\circ} 57^{\prime} 23.01^{\prime \prime}$ & Drying process-centrifuge \\
\hline 3 & $26^{\circ} 46^{\prime} 55.52^{\prime \prime}$ & $50^{\circ} 57^{\prime} 22.93^{\prime \prime}$ & Washing process \\
\hline 4 & $26^{\circ} 46^{\prime} 55.52^{\prime \prime}$ & $50^{\circ} 57^{\prime} 23.53^{\prime \prime}$ & Raffia storage \\
\hline 5 & $26^{\circ} 46^{\prime} 56.12^{\prime \prime}$ & $50^{\circ} 57^{\prime} 23.61^{\prime \prime}$ & Extrusion process-extruder \\
\hline 6 & $26^{\circ} 46^{\prime} 56.83^{\prime \prime}$ & $50^{\circ} 57^{\prime} 23.75^{\prime \prime}$ & Warehouse \\
\hline 7 & $26^{\circ} 46^{\prime} 54.16^{\prime \prime}$ & $50^{\circ} 57^{\prime} 26.68^{\prime \prime}$ & Office \\
\hline 8 & $26^{\circ} 46^{\prime} 56.69^{\prime \prime}$ & $50^{\circ} 57^{\prime} 22.66^{\prime \prime}$ & bottom of factory - west \\
\hline 9 & $26^{\circ} 46^{\prime} 54.86^{\prime \prime}$ & $50^{\circ} 57^{\prime} 23.93^{\prime \prime}$ & factory of bottom - east \\
\hline 10 & $26^{\circ} 46^{\prime} 57.47^{\prime \prime}$ & $50^{\circ} 57^{\prime} 23.08^{\prime \prime}$ & Plant gate \\
\hline 11 & $26^{\circ} 46^{\prime} 57.51^{\prime \prime}$ & $50^{\circ} 57^{\prime} 23.08^{\prime \prime}$ & Parking lot \\
\hline 12 & $26^{\circ} 46^{\prime} 57.97^{\prime \prime}$ & $50^{\circ} 57^{\prime} 22.98^{\prime \prime}$ & First sampling point-street \\
\hline 13 & $26^{\circ} 46^{\prime} 58.03^{\prime \prime}$ & $50^{\circ} 57^{\prime} 24.56^{\prime \prime}$ & Second sampling point-street \\
\hline 14 & $26^{\circ} 46^{\prime} 56.09^{\prime \prime}$ & $50^{\circ} 57^{\prime} 24.33^{\prime \prime}$ & Plant surroundings-effluent treatment system
\end{tabular}

* Sample points were analyzed according to their interaction.

\section{Results}

Table 2 shows the noise values in $\mathrm{dB}(\mathrm{A})$ sampled at different stages of the plastic recovery process of

the plant under study (1).

Table 2: Analysis of noise generation in different points and stages of production in operation

\begin{tabular}{|c|c|c|c|c|c|}
\hline \multirow{2}{*}{ Score } & \multicolumn{5}{|c|}{ Analysis of noise emission } \\
\hline & Not operating & Extrusion process & Washing process & Total operation & Mean \\
\hline 1 & $49.2 \mathrm{CD}$ & $71.2 \mathrm{ABC}$ & $84.4 \mathrm{AB}$ & $87.1 \mathrm{~A}$ & $73.0 \mathrm{~A}$ \\
\hline 2 & $53.9 \mathrm{ABC}$ & $82.9 \mathrm{CD}$ & $92.0 \mathrm{CD}$ & $92.1 \mathrm{CB}$ & $80.2 \mathrm{~A}$ \\
\hline 3 & $49.7 \mathrm{CD}$ & $66.6 \mathrm{D}$ & $95.9 \mathrm{ABC}$ & $98.0 \mathrm{ABC}$ & $77.6 \mathrm{~A}$ \\
\hline 4 & 43.4 D & $63.9 \mathrm{AB}$ & 79.2 CB & 84.8 BC & $67.8 \mathrm{~A}$ \\
\hline 5 & $49.3 \mathrm{CD}$ & $44.8 \mathrm{AB}$ & $83.7 \mathrm{~A}$ & $86.4 \mathrm{~A}$ & 66.1 A \\
\hline 6 & $41.4 \mathrm{D}$ & $53.8 \mathrm{~A}$ & $68.7 \mathrm{D}$ & $74.6 \mathrm{BC}$ & $59.6 \mathrm{~A}$ \\
\hline 7 & $46.1 \mathrm{D}$ & $56.3 \mathrm{~B}$ & $58.1 \mathrm{ABC}$ & $61.0 \mathrm{BC}$ & $55.4 \mathrm{~A}$ \\
\hline 8 & $44.8 \mathrm{D}$ & $54.6 \mathrm{ABC}$ & $72.2 \mathrm{CB}$ & $73.7 \mathrm{ABC}$ & $61.3 \mathrm{~A}$ \\
\hline 9 & $45.2 \mathrm{D}$ & $66.5 \mathrm{CB}$ & $66.2 \mathrm{CD}$ & $70.8 \mathrm{CD}$ & 62.2 A \\
\hline 10 & $63.2 \mathrm{AB}$ & $50.6 \mathrm{~A}$ & $58.6 \mathrm{D}$ & $63.3 \mathrm{D}$ & $58.9 \mathrm{~A}$ \\
\hline 11 & $54.4 \mathrm{BC}$ & $66.5 \mathrm{~B}$ & $74.6 \mathrm{BC}$ & $81.4 \mathrm{CB}$ & $69.2 \mathrm{~A}$ \\
\hline 12 & $63.3 \mathrm{~A}$ & $50.6 \mathrm{BC}$ & $61.7 \mathrm{~A}$ & $62.5 \mathrm{AB}$ & $59.5 \mathrm{~A}$ \\
\hline 13 & $63.1 \mathrm{AB}$ & $52.2 \mathrm{ABC}$ & $64.7 \mathrm{AB}$ & $59.6 \mathrm{AB}$ & $59.9 \mathrm{~A}$ \\
\hline \multirow[t]{2}{*}{14} & $60.1 \mathrm{AB}$ & $62.3 \mathrm{~A}$ & $72.6 \mathrm{AB}$ & $70.6 \mathrm{BC}$ & $66.4 \mathrm{~A}$ \\
\hline & \multicolumn{5}{|c|}{ - } \\
\hline AVERAGE & $51.9 \mathrm{c}$ & $60.2 \mathrm{bc}$ & 73.8 a & 76.1 a & $65.5 \mathrm{ab}$ \\
\hline
\end{tabular}

Values preceding the same letters, lowercase in the row and upper case in the column, do not differ significantly from each other according to the Tukey's test $(P \leq 0.05)$.

Figure 4demonstrates the average generation of noise values through on-site analysis in the plant under study.

The emission of sound pressure in the study was associated with the noise generation source, where the processes of washing and extrusion of plastic were the main sources of noise and could be related to environmental pollution, since noise was a silent agent needing attention in industrial areas. Figure 4 shows the generation of noise during the sampling period, presenting higher noise generation in the total operation process, reaching almost $100 \mathrm{~dB}(\mathrm{~A})$. This could be associated with the adverse effects on the environmental quality and plant employees. Moreover, the non-operation process was along with noise generation due to being in an industrial area with $63.3 \mathrm{~dB}(\mathrm{~A})$. The study findings indicated that in total operation, the plant generated a noise amount of above the value established by the pertinent rate of $70 \mathrm{~dB}(\mathrm{~A})$. 

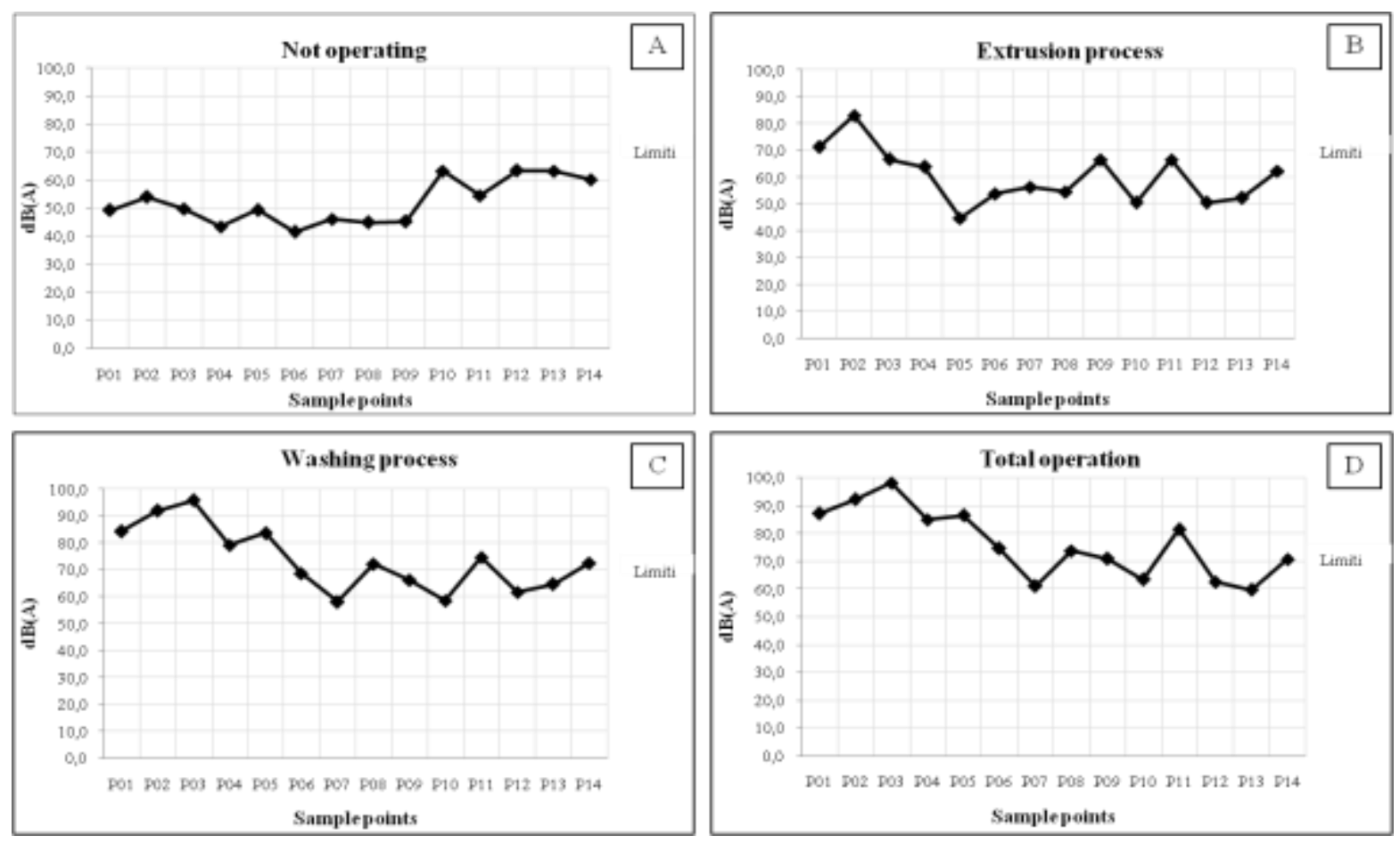

Figure 4: Analysis of noise emission in different sectors of the plant under study: (A) Lack of operation of any machine; (B) Operation of the extrusion process only; (C) Operation of the washer; and (D) Total operation of all processes

\section{Discussion}

The study presented variations of noise production for different processes of the plant among the sampling points located near the plastic grinding, washing, drying, and extrusion process sites. These were the main points with high emission levels of the sound pressure (P01, P02, P03, and P05). This issue is attributed to the type of recycling process, since it is a mechanical process with little human interaction. To minimize the noise emitted in the industrial processes, it is necessary to revise and restructure the architectural projects, in addition to relocating or replacing the equipment used in the process. Moreover, the use of sound insulation is necessary in order to reduce the noise paths and hinder the noise penetrating outside the production site (25). Real-time spectrum monitoring is a mechanism used in the control of the machines' functioning to evaluate workers exposure to noise (26). The use of noise mapping provides more information for the monitoring and hence the actions to be taken (27).

Due to the characteristics of the plant and location in the industrial area of the municipality, the plant under study generated noise rates ranging from 41.4 to $63.4 \mathrm{~dB}(\mathrm{~A})$, showing interaction of the study area with noise emission. However, according to the sampling points, the study companies do not affect the environmental sound quality of the region to its surroundings (Figure 2). This process of noise generation may be associated with the process of moving trucks in the study area, but it may also be entirely connected with the type of ground cover for traffic of trucks, cars, and other vehicles (28).
However, the study area presented interaction of the two agents (factory streets) linked to the processes of generation of noise, as can be observed in figure 2 .

During the total operation process, with all the equipment in operation the plant noise generation varied from 59.6 to $98.0 \mathrm{~dB}(\mathrm{~A})$, showing that the plant under study generated high noise levels. Therefore, it is necessary to train the employees and deliver personal protective equipment to them in order to minimize their exposure to noise. Activities with noise emission above $85 \mathrm{~dB}(\mathrm{~A})$ are considered as unhealthy (29). For more information on the health-care process, it is necessary to perform a noise exposure analysis on the plant workers (30). For the development of this activity, "plastic recycling" requires the use of ear protectors in order to minimize the damages of noise on the workers and employees (31).

The industries generally need to seek ways to reduce the exposure of the employees with the emission of agents harmful to their health in order to comply with regulatory laws, hence they invest in personal protection equipment. Because employees in the study area are exposed to the noise agent, they need insularity on their payroll from the coolers (32). It is necessary to develop the audiometry analysis on the employees in order to examine and prevent the harms of noise emission of the plants on the workers and employees (33). Aiming at the environmental comfort of some residents of the region near the study area, the study plant comply with the environmental regulations related to environmental comfort. 
Meanwhile, the plant produces 50.6 to $64.7 \mathrm{~dB}(\mathrm{~A})$ noise during the operation of the sampling points that have interaction with the surrounding area (P10 and P13).However, it is necessary to develop continuous monitoring of noise emission in the present plant, since the tolerance value established by the relevant legislation is $70 \mathrm{~dB}(\mathrm{~A})$ daily. Noise is a silent agent that needs to be minimized which can be fulfilled through continuous noise monitoring system (34).

\section{Conclusion}

According to the study, it can be concluded that the plant under study is in environmental compliance with the emission of noise, as the sampling points near the residences presented inferior values as set by the pertinent laws and norms. However, even while being compliant with environmental regulations, the plant needs to develop means to reduce the noise emission. Since the centrifugation of drying of the crushed raffia generated greater noise amounts, insulation of this area seems more necessary compared to other processes. In general, any production process with noise generation above the specified levels needs an improvement, including noise insulation of the area with a high level of noise emission or providing ear protectors to the staff in areas with noise generation not exceeding the daily dose prescribed in NR15 or NHO 01.

\section{Acknowledgement}

The study was designed and financially supported by the University Alto Vale do Rio do Peixe (UNIARP). We would like to appreciate all the individuals involved in this research project, particularly Professor Antonio Pedro Tessaro.

\section{Conflict of interest: None declared.}

\section{References}

1- Mano EB, Pacheco EBAV, Bonelli CMC. Environment, pollution and recycling. 2nded. São Paulo: Blucher; 2010.

2- Braga B, Hespanhol I, Conejo JGL, Mierzwa JC, Barros MTL, Spencer M, et al.. Introduction to environmental engineering-The challenge of sustainable development. 2nded. São Paulo: Pearson Prentice Hall; 2006.

3- Fiorillo, CAP. Brazilian environmental law course. 4thed. São Paulo: Saraiva; 2003. P116.

4- Brazil. Resolution CONAMA 001/90 of March 08, 1990. Provides criteria and standards for noise emission, industrial activities. Brasília; 1990. Available from: http://www.mma.gov.br/port/conama/legiabre.cfm ?codlegi $=98$.

5- Carmo, LIC. Effect of environmental noise on the human organism and its auditory manifestations. [MSc thesis]. Goiânia, Goiás: Center for Specialization in Clinical Speech-Language Pathology Audiology Alínica; 1999.

6- FyhriA, Aasvang GM. Noise, sleep and poor health: Modeling the relationship between road traffic noise and cardiovascular problems. Sci Total Environ 2010; 408(21):4935-42.

7- Campos RFF. Evaluation and characterization of insalubrity by exposure to noise in a plastic recycling company. [MSc thesis]. Caçador, Santa Catarina, Brazil: University Alto Vale do Rio do Peixe; 2016.

8- Lacerda ABM, Magni C, Morata TC, Marques JM, Zannini PHT. Urban environment and sound perception. Environment \& Society 2005; 8(2):113.

9- Cunha DF, Resende AA. Measurement of noise analysis in small machine shop for machining processes. Paper presented at: The 32nd National Meeting of Production Engineering; 2012 October 15-18; Bento Gonçalves, Rio Grande do Sul, Brazil.

10- Venturoli F, Fiefler NC, Minetti LJ, Martins, IS. Evaluation of noise level in joinery in Distrito Federal, Brazil. Brazilian Journal of Agricultural and Environmental Engineering 2003; 7(3):547-51.

11- Girardi G, Sellitto MF. Measurement and recognition of physical risk concerning noise in a company of furniture industry in Rio Grande do Sul highland. Technological Studies in Engineering 2011; 7(1):12-23.

12- Formigoni CEM. Evaluation and characterization of insalubrity by exposure to environmental noise of workers of an industrial waste management company. [MSc thesis] Curitiba: Federal Technological University of Parana; 2013.

13- Takahashi S. Measurement of noise in a small metalworking company according to NR-15. Paper presented at: The 22nd Symposium on Production Engineering; 2015 November 7-9; Bauru, São Paulo, Brazil.

14- Barcelos DD. Analysis of noise risk in clothing industry.Journal Center for Specialization in Clinical Speech Pathology 2014; 16(1):39-49.

15- Tavares VC. The crushing process of the company Britamix in the municipality of Queimadas/PB and the analysis of noise pollution. Brazilian Journal of Physical Geography 2016; 9(2):399-412.

16- Lacerda ABM, Magni C, Morata TC, Marques JM, Zannini PHT. Urban environment and sound perception. Environment \& Society 2005; 8(2):113.

17- King RP, Davis, JR. Community noise: health effects and management. Int $\mathrm{J}$ Hyg Environ Health 2006; 206(2):123-31.

18- Carmo LIC. Effect of environmental noise on the human organism and its auditory manifestations. Goiânia: Center for Clinical Phono- Audiology Specialization Clinical Audiology; 1999.

19- Moudon AV. Real Noise from the Urban Environment: How Ambient Community Noise Affects Health and What Can Be Done About It. Am J Prev Med 2009; 37(2):167-71.

20- Brazilian Association of Technical Standards, ABNT (2001). NBR I0.151 - Acoustics - Evaluation 
of noise in inhabited areas, aiming at the comfort of the community Procedure. Rio de Janeiro; 2001.

21- Silva FAS,Azevedo CAV. Main components analysis in the software assistat statistical attendance.Paper presented at: The World Congress on Computers in Agriculture; 2009 June 21-24; Reno, Nevada, United States.

22- Taghizadeh R, Zare M, Zare S. Mapping of noise pollution by different interpolation methods in recovery section of Ghandi telecommunication Cables Company. Journal of Occupational Health and Epidemiology 2013; 2(1-2):1-11.

23- Brasil. Ministry of Labor and Employment. Activities and Unhealthy Operations, Portaria SIT n.․ 203. Brasília: Ministry of Labor and Employment; 2001.
24- Brasil, Ministry of Labor and Employment. Occupational Hygiene Standard - OHS 01 Occupational exposure to noise assessment, Fundacentro. Brasília: Ministry of Labor and Employment; 2001.

25- Souza LE, Dorneles FT, Zago LEO, Abichequer LA, Neto RO, Gonqalves IG, et al. Noise and vibration impact assessment in city limits situation. Environmental Monographs 2015; 14:33-43.

26- Barcelos DD, Ataíde SG. Analysis of noise risk in clothing industry. Journal Center for Specialization in Clinical Speech Pathology 2014; 16(1):39-49.

27- Lourenço GMS, da Silveira DD. Environmental education, developing activities to minimize noise in school. Electronic Journal in Environmental Management, Education and Technology 2011; $4(4): 546-57$. 